\title{
Probiotics in Taiwan from Bench to Clinical
}

\section{Chun-Yan Yeung ${ }^{1 \star}$ and Hung-Chang Lee ${ }^{1,2}$}

${ }^{1}$ Department of Pediatrics, MacKay Children's Hospital, MacKay Medical College, Taipei, Taiwan

${ }^{2}$ Taipei Medical University, Taipei, Taiwan

Probiotics are defined as live microorganisms that, when administered in adequate amounts, confer a health benefit on the host. The field of probiotics has evolved and progressed over past years leading to a global and diversified market today. Over the past years, the number of studies supporting the health benefits of feeding probiotics to infants and children has increased tremendously.

A prospective cohort study on the use of probiotic supplement among young children in Taiwan showed approximately half the children received probiotic supplements before the age of 18 months. The study shows that probiotic supplement usage among young children is associated with a more socially advantaged circumstance and certain child health factors, such as eczema, diarrhea, and constipation. Parents might use probiotic supplements for prevention or treatment of child diseases.

In the past decade, our TSPGHAN (Taiwan Society of Pediatric Gastroenterology, Hepatology and Nutrition) colleagues have published quite a lot of studies on probiotics, including basic laboratory researches and clinical trials on several commercial products. Several in-vitro, in-vivo and animal studies tried to explore the mechanisms of certain probiotic strains in the anti-inflammation and immunomodulation effects. In vitro and in vivo studies include: role of Lactobacillus rhamnosus in inhibition of inflammation and enhancing barrier integrity of epithelium in a co-culture model using Caco 2/peripheral blood mononuclear cells, pre-inoculation with the probiotic Lactobacillus acidophilus early in life effectively inhibits murine Citrobacter rodentium colitis, effect of probiotics Lactobacillus acidophilus on Citrobacter rodentium: the role of dendritic cells, oral administration of Lactobacillus plantarum K68 ameliorates DSSinduced ulcerative colitis in $\mathrm{BALB} / \mathrm{c}$ mice via the anti-inflammatory and immunomodulatory activities, in-vitro prevention of Salmonella lipopolysaccharide induced damages in epithelial barrier function by various Lactobacillus strains, amelioration of chemotherapy-induced intestinal mucositis by orally administered probiotics in a mouse model, effects of probiotic supplementation on glucose homeostasis and obesity in obese mice model, live and heat-killed Lactobacillus rhamnosus GG upregulate gene expression of pro-inflammatory cytokines in 5-fluorouracil-pretreated Caco 2 cells, probiotic BioThree induces Th1 and anti-inflammatory effects in PBMC and dendritic cells, etc.

Clinical trials include: Lactobacillus casei rhamnosus in preventing cholangitis in biliary atresia after Kasai operation, dose-dependent effect of Lactobacillus rhamnosus on quantitative reduction of faecal rotavirus shedding in children, probiotics (Bacillus mesentericus Enterococcus faecalis, Clostridium butyricum) have clinical, microbiologic, and immunologic efficacy in acute infectious diarrhea, oral probiotics in preventing necrotizing enterocolitis in very low birth weight preterm infants (a multicenter, randomized, controlled trial), Clostridium butyricum miyairi enhance the medical efficacy on constipation and modify intestinal microflora in children with functional constipation, Lactobacillus casei rhamnosus (Lcr35) in children with chronic constipation, etc.

\section{Publication History:}

Received: September 18, 2017

Accepted: October 28, 2017

Published: October 30, 2017

\section{Keywords:}

Probiotics, Nutrition, In-vitro, In-vivo, Pediatric diseases

Our colleagues also published several review articles on probiotics including gut microbiota and the development of pediatric diseases, probiotics and the mechanism of necrotizing enterocolitis in the renowned literatures.

Several situations and limitations within the probiotic field that are of current interest and concern remain, including use of systematic reviews and meta-analyses for clinical applications of probiotics, challenges to doing human research on probiotics, medical recommendations for probiotic use, usage of single strains versus multiple strains, and safety considerations for probiotics used among particular populations, such as infants and children and immunocompromised patients.

In conclusion, accumulating evidence of the probiotic benefits has led to greater consumption of probiotic supplements. However, data on probiotic supplementation, especially safety issue, in the pediatric population are scant. The greatest need in the probiotic field remains well-conducted and well-reported human trials, and to better define the functionality of probiotics for different indications and populations.

\section{Competing Interests}

The authors declare that they have no competing interests.

\section{References}

1. Bu LN, Chang MW, Ni YH, Chen HL, Cheng CC, et al. (2007) Lactobacillus casei rhamnosus Lcr35 in children with chronic constipation. Pediatri Int 49: $485-490$.

2. Lin HC, Hsu CH, Chen HL, Chung MY, Hsu JF, et al. (2008) Oral Probiotics prevent necrotizing enterocolitis in very low birth weight preterm infants: a multicenter, randomized, controlled trial. Pediatrics 122: 693-700.

3. Fang SB, Lee HC, Hu JJ, Hou SY, Liu HL, et al. (2009) Dose-dependent effect of Lactobacillus rhamnosus on quantitative reduction of faecal rotavirus shedding in children. J Trop Pediatr 55: 297-301.

4. Hua MC, Lin TY, Lai MW, Kong MS, Chang HJ, et al. (2010) Probiotic BioThree induces Th1 and anti-inflammatory effects in PBMC and dendritic cells. World J Gastroenterol 16: 3529-3540

"Corresponding Author: Prof. Chun-Yan Yeung, Department of Pediatrics MacKay Children's Hospital, MacKay Medical College, Taipei, Taiwan; E-mail: cyyeung1029@mmh.org.tw

Citation: Yeung CY, Lee HC (2017) Probiotics in Taiwan from Bench to Clinical. Int J Pediatr Neonat Care 2: 127. doi: https://doi.org/10.15344/2455-2364/2017/127

Copyright: (c) 2017 Yeung et al. This is an open-access article distributed under the terms of the Creative Commons Attribution License, which permits unrestricted use, distribution, and reproduction in any medium, provided the original author and source are credited. 
5. Chen CC, Kong MS, Lai MW, Chao HC, Chang KW, et al. (2010) Probiotics have clinical, microbiologic, and immunologic efficacy in acute infectious diarrhea. Pediatr Infect Dis J 29: 135-138.

6. Chen YC, Chien YW, Chang PJ, Hsieh WS, Chen PC, et al. (2012) Probiotic supplement use among young children in Taiwan: a prospective cohort study. Plos One 7: e43885.

7. Yeung CY, Chiang Chiau JS, Chan WT, Jiang CB, Cheng ML, et al. (2013) In-vitro prevention of Salmonella lipopolysaccharide-induced damages in epithelial barrier function by various Lactobacillus strains. Gastroenterology Research and Practice 2013: 973209.

8. Chen CC, Walker WA. (2013) Probiotics and the mechanism of necrotizing enterocolitis. Seminars in Pediatric Surgery 22: 94-100.

9. Fang SB, Shih HY, Huang CH, Li LT, Chen CC, et al. (2014) Live and heatkilled Lactobacillus rhamnosus GG upregulate gene expression of proinflammatory cytokines in 5-fluorouracil-pretreated Caco-2 cells. Support Care Cancer 22: 1647-1654.

10. Yeung CY, Chan WT, Jiang CB, Chang SW, Cheng ML, et al. (2015) Amelioration of chemotherapy-induced intestinal mucositis by orally administered probiotics in a mouse model. PLOS One 10: e0138746

11. Lien TH, Bu LN, Wu JF, Chen HL, Chen AC, et al. (2015) Use of Lactobacillus casei rhamnosus to prevent cholangitis in biliary atresia after Kasai operation. JPGN 60: 654-658.

12. Lu CY, Ni YH. (2015) Gut microbiota and the development of pediatric diseases. J Gastroenterol 50: 720-726. 